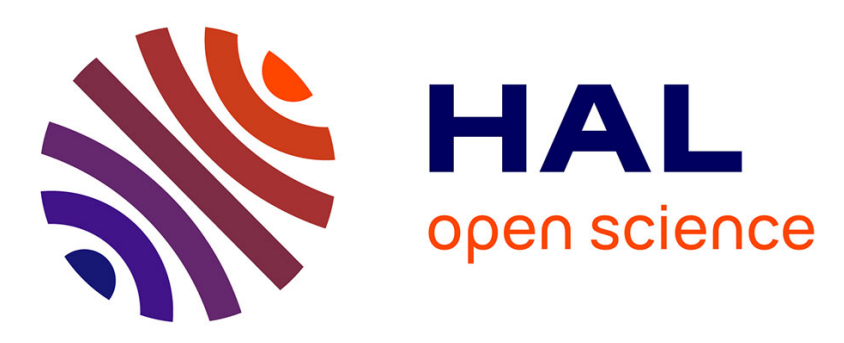

\title{
Radio Wave Propagation in Arched Cross Section Tunnels - Simulations and Measurements
}

Emilie Masson, Pierre Combeau, Marion Berbineau, Rodolphe Vauzelle, Yannis Pousset

\section{- To cite this version:}

Emilie Masson, Pierre Combeau, Marion Berbineau, Rodolphe Vauzelle, Yannis Pousset. Radio Wave Propagation in Arched Cross Section Tunnels - Simulations and Measurements. Journal of Communication, 2009, 4 (4), pp.276-283. 10.4304/jcm.4.4.276-283 . hal-00434377

\section{HAL Id: hal-00434377 \\ https://hal.science/hal-00434377}

Submitted on 26 Oct 2012

HAL is a multi-disciplinary open access archive for the deposit and dissemination of scientific research documents, whether they are published or not. The documents may come from teaching and research institutions in France or abroad, or from public or private research centers.
L'archive ouverte pluridisciplinaire HAL, est destinée au dépôt et à la diffusion de documents scientifiques de niveau recherche, publiés ou non, émanant des établissements d'enseignement et de recherche français ou étrangers, des laboratoires publics ou privés. 


\title{
Radio Wave Propagation in Arched Cross Section Tunnels - Simulations and Measurements
}

\author{
E. Masson ${ }^{* 1}$ \\ ${ }^{* 1}$ ALSTOM-Transport, Saint-Ouen, France \\ emilie.masson@inrets.fr \\ P. Combeau ${ }^{* 2}$, M. Berbineau* ${ }^{* 3}$, R. Vauzelle ${ }^{* 2}$, Y. Pousset $^{* 2}$ \\ ${ }^{* 2}$ Xlim UMR CNRS 6172, SIC department (Signal Image Communication), Chasseneuil-du-Poitou, France \\ ${ }^{* 3}$ INRETS French National Institute for Transport and Safety Research, Villeneuve d'Ascq, France \\ combeau@sic.sp2mi.univ-poitiers.fr, marion.berbineau@inrets.fr, \{vauzelle,pousset\}@sic.sp2mi.univ-poitiers.fr
}

\begin{abstract}
For several years, wireless communication systems have been developed for train to infrastructure communication needs related to railway or mass transit applications. The systems should be able to operate in specific environments, such as tunnels. In this context, specific radio planning tools have to be developed to optimize system deployment. Realistic tunnels geometries are generally of rectangular cross section or arched shape. Furthermore, they are mostly curved. In order to calculate electromagnetic wave propagation in such tunnels, specific models have to be developed. Several works have dealt with retransmission of GSM or UMTS [1], [2]. Few theoretical or experimental works have focused on $2.4 \mathrm{GHz}$ or $5.8 \mathrm{GHz}$ bands [3]. In this paper, we propose an approach to model radio wave propagation in these frequency bands in arched shape cross section straight tunnels using tessellation in multi-facets. The model is based on a Ray-Tracing tool using the image method. The work reported in this paper shows the propagation loss variations according to the shape of tunnels. A parametric study on the facets size to model the cross section is conducted. The influence of tunnel dimensions and signal frequency is examined. Finally, some measurement results in an arched cross section straight tunnel are presented and analyzed in terms of slow fadings and fast fadings.
\end{abstract}

Index Terms-Radio wave propagation, Arched shape tunnels, Ray tracing, tessellation, E-field measurements.

\section{INTRODUCTION}

The need for wireless communication systems is increasing for train to ground or train to train communications in the railway or mass transit domains. These systems are developed to satisfy operational needs, such as traffic management, maintenance, information applications and security of passengers and staff. Among these applications we can mention control-command systems and also high data-rate transmissions for multimedia or other operational applications. Several systems are already deployed in the world using free propagation in tunnels in the $2.4 \mathrm{GHz}$ or $5.8 \mathrm{GHz}$ bands (Urbalis system for ALSTOM, Airlink $\AA$ system used by SIEMENS). The prediction of radio coverage levels is required to optimize deployment phases and ensure availability and robustness of the links. Generally, minimal field levels are required to guarantee key performance indicators related to safety constraints or QoS requirements for video transmissions. In tunnels, the usual laws of free space propagation are no longer valid and the propagation phenomenon has to be specifically analyzed to develop statistical models which are easy to use to predict radio coverage [4]. Thus, up to now, the case of tunnel areas is generally treated via intensive measurement campaigns. The development of specific models is then very relevant.

The paper focuses on results obtained at $2.4 \mathrm{GHz}$ and $5.8 \mathrm{GHz}$ bands in arched shape cross section straight tunnels. The model is based on a Ray-Tracing tool using the image method. A method of tessellation in multifacets of the cross section is used, and obtained results are compared to measurements. The first part of the paper presents different modeling techniques that can be used to describe radio wave propagation in tunnels. The second part details the considered method of tessellation. Particularly, obtained results in arched shape cross section straight tunnels at $1 \mathrm{GHz}$ are presented and compared to existing results. The influence of shape of tunnels is highlighted and a parametric study on the number of facets to model the cross section is realized. The third part of the paper is devoted to the study of the influence of tunnel dimensions and signal frequency, focusing on $2.4 \mathrm{GHz}$ and $5.8 \mathrm{GHz}$ bands. The last part of the paper is dedicated to measurement results obtained in an arched shape cross section tunnel. Comparisons between simulations and measurements are realized in terms of slow fadings and fast fadings. Finally, conclusions and perspectives of the work are given.

\section{SEVERAL METHODS OF RADIO WAVE PROPAGATION MODELING IN TUNNELS}

In order to describe the radio wave propagation in tunnels, several modeling approaches can be set up. The numerical resolution of Maxwell's equations would be an ideal solution. However, this kind of technique is not 
feasible due to the enormous computational burden. A more conventional way to solve the problem is given by modal theory. The tunnel is here treated as a hollow waveguide with dielectric boundaries. Unfortunately, analytical expressions of the different constants, such as cut-off frequency and wave impedance, only exist for few canonical types of configuration, e.g. rectangular or circular cross section waveguides [5]. The prediction of radio wave propagation with an adequate accuracy in finite time is given by ray optics solutions. These solutions can be adopted in tunnels because dimensions in tunnels are generally large compared to the considered wavelength (frequency above $1 \mathrm{GHz}$ ). Several methods based on the ray-optical modeling approach have been proposed. They use ray launching [2], [6], the image method [7] or combination of each [1]. They all consider only the case of straight and rectangular tunnels. The classical approach of Ray-Tracing techniques cannot be transposed to the case of curved surfaces. Indeed, the image method is not applicable because of the infinite line of images of one source compared to a single point for plane surface. For the ray launching, the concept of reception sphere is no longer valid for curved surfaces because of the non-conservation of reflection angles [8]. The first conceivable solution to model the propagation in environments where curved surfaces are present is the development of a completely novel model based on ray optics, as in [8]. The second option for non-rectangular cross section straight tunnels is to consider the equivalent rectangular cross section tunnel with an equal area. The last solution is to tessellate geometries into multiple planar facets, as proposed in [1], [7], [9].

\section{MODELING CURVED WITH FACETS - INFLUENCE OF NUMBER OF FACETS}

A Ray-Tracing method [11] combined to a tessellation of the curvature of the tunnel will be used. First, the simulation tool is presented as well as the tessellation principle. Then, simulation configurations are detailed. Finally, a parametric study on the facets size is realized to model the arched section.

\section{A. Method of tessellation}

The Ray-Tracing method consists of a direct research of geometric paths followed by the waves. It allows us to determine exactly the set of paths from a transmitter to a receiver. This technique is based on the image theory based on Snell-Descartes formulas. From these paths, the Electric field is computed from Geometrical Optic (GO) laws and from Fresnel coefficients. In the case of a curved surface, one source generates an infinite number of images. To solve this problem, we choose to approximate the curved surface by facets. Several problems appear, such as the position of the facets and the optimal size of facets. In [9], a first approach of tessellation of a curved surface is presented in the case of a 2D curvature. A method developed in [1] uses triangular facets to model the curved surface. A hybrid method based on a Shooting and Bouncing Ray (SBR) combined with the image theory is tested in some particular configurations of tunnels. Finally in [7], a tool developed for planning and design of wireless systems is presented. It is based on Ray-Tracing techniques. Similar results to Cheng \& Jeng [1] are obtained. The use of the tessellation raises the problem of the size of facets to be used to represent a given curvature. A compromise has to be found on the number of facets retained. It has to be sufficient to represent the geometry of the arched section but not too large to stay in the limit of validity of the physical model based on a high frequency approach. None of the mentioned publications gives criteria to determine the optimal number of facets.

\section{B. Configurations of simulations at $1 \mathrm{GHz}$}

Three configurations of simulations of straight tunnels with equivalent cross section area from Cheng \& Jeng [1] are considered, illustrated on Figure 3.1: tunnel A is a rectangular cross section tunnel, tunnel $\mathrm{B}$ represents the intermediate tunnel, an arched cross section tunnel modeled with 3 facets, and tunnel $\mathrm{C}$ is an arched cross section tunnel modeled with $n$ facets. A $1 \mathrm{GHz}$ frequency is considered. The transmitting and receiving antennas are dipoles vertically polarized and placed respectively in $(4,0,4.5) \mathrm{m}$ and $(2.1, y, 1.5) \mathrm{m}$, where $y$ represents the longitudinal direction of the tunnel and varies from $10 \mathrm{~m}$ to $150 \mathrm{~m}$ with a step of $1 \mathrm{~m}$. Results for tunnels A and B are rapidly obtained. For tunnel $\mathrm{C}$, a study on the number of facets used to approximate the arched section has to be realized. To guarantee a valid physical model, the high frequency approach requires a size of facets $d>>\lambda$, where $\lambda$ is the wavelength. We assume that these conditions are respected for $d>2 \lambda$. Given the tunnel dimensions, the condition on the number of facets $n$ is as follows:

$$
4 \leq n \leq 20
$$

\section{Simulation Results}

All the results presented are given in terms of signal attenuation (in $\mathrm{dB}$ ) depending on the distance between transmitter and receiver. Only the reflection phenomenon is considered in the simulations. It represents the dominant effect in an empty tunnel: there is no transmission because of the tunnel walls properties and no diffraction because of the lack of edge.

All the results presented in the paper are displayed with the same scale in order to facilitate the comparisons between the different curves.
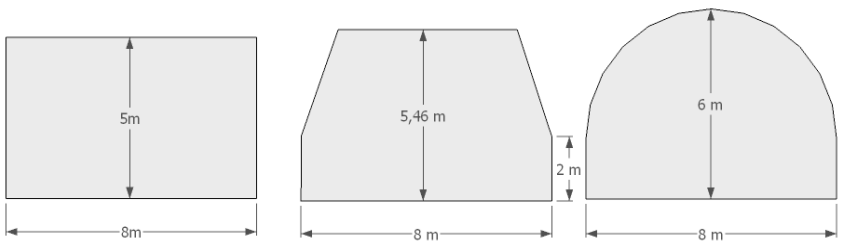

Figure 3.1: Geometry of tunnels 

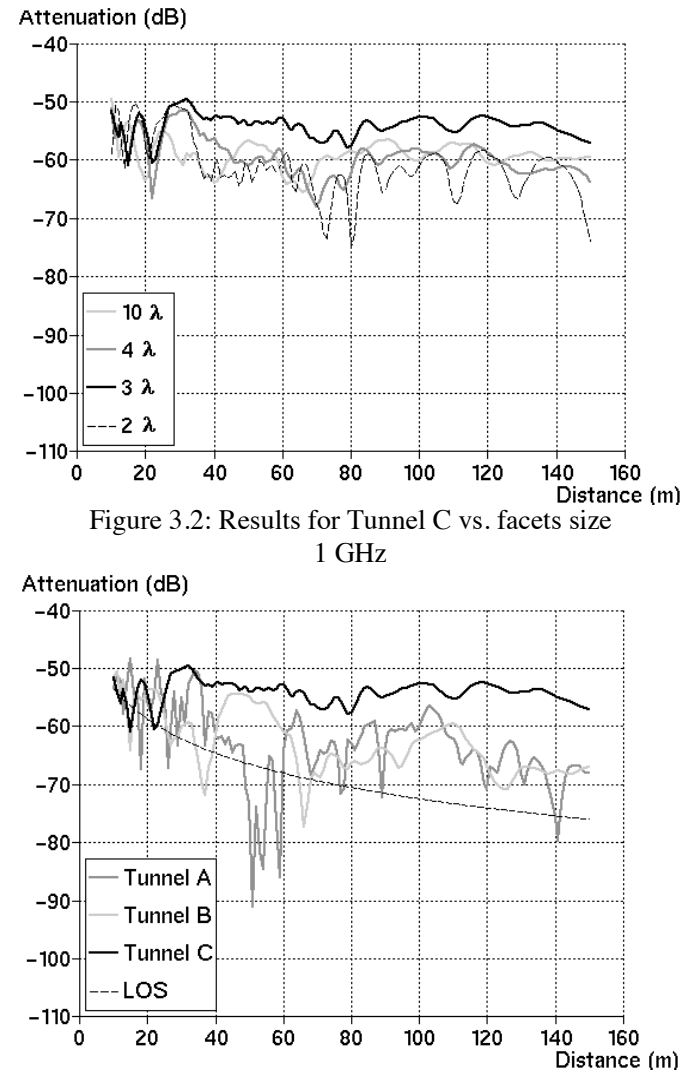

(a)

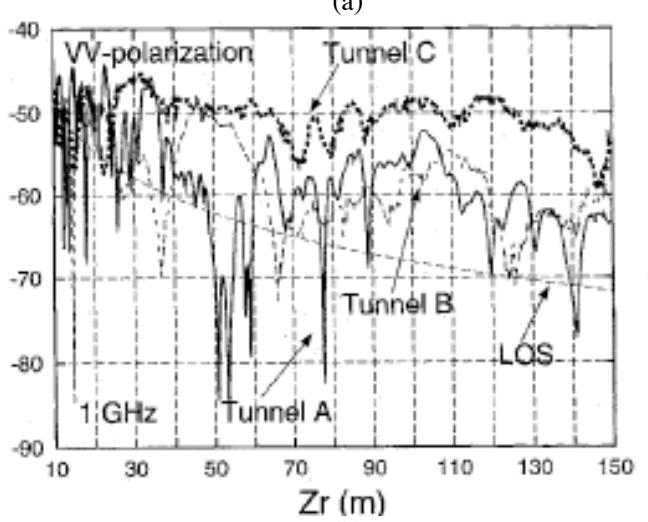

(b)

Figure 3.3: Results for Tunnels A, B and C facets size: $3 \lambda$ (a) compared to results from [1] (b)

Figure 3.2 presents the results obtained for tunnel C, depending on the facets size. An important signal level variation can be observed from one configuration to another. Results obtained in simulations are compared to results presented in [1] considering an arched section approximated by facets with a size of $3 \lambda$, which gives the higher signal level. It is important to note that the higher level does not inevitably correspond to the real signal level. We will see later the comparison with measurement results in order to validate, or not, this observation. Figure 3.3 shows the results obtained for tunnels A, B and $\mathrm{C}$ and highlights a concordance with results presented in [1]. A «focusing » effect in terms of energy can be observed for the arched section compared to the rectangular section. This phenomenon is characterized by smaller depth fadings and a higher global signal level. The signal level is also compared to the free space case (dotted line), in Line Of Sight (LOS). This result highlights the guided effect in tunnels, compared to free space.

\section{INFLUENCE OF FREQUENCY AND TUNNEL DIMENSIONS}

\section{A. Frequency influence}

In this part, the frequency varies for similar tunnel geometry. High frequency conditions have to be respected. At $2.4 \mathrm{GHz}$, equation (1) becomes:

$$
4 \leq n \leq 50
$$

and at $5.8 \mathrm{GHz}$, this condition becomes:

$$
4 \leq n \leq 120
$$

Figures 4.1 and 4.3 illustrate simulation results for tunnel $\mathrm{C}$ at the two frequencies. Some significant variations can be observed from one result to another. Figures 4.2 and 4.4 show, respectively at $2.4 \mathrm{GHz}$ and $5.8 \mathrm{GHz}$, the results for the 3 tunnels $\mathrm{A}, \mathrm{B}$ and $\mathrm{C}$ (considering a facets size providing the higher signal level).

The «focusing » effect observed at $1 \mathrm{GHz}$ is greatly attenuated at $2.4 \mathrm{GHz}$ and $5.8 \mathrm{GHz}$. The number of facets and the size of the facets have an important effect on the signal level. It has to be noticed that these conclusions concern tunnels of large dimensions ( $8 \mathrm{~m} \mathrm{x} 5 \mathrm{~m}$ ), such as TGV tunnels where GSM-R is deployed, or large motorway tunnels. We will then consider tunnels of smaller dimensions corresponding to mass transit tunnels.

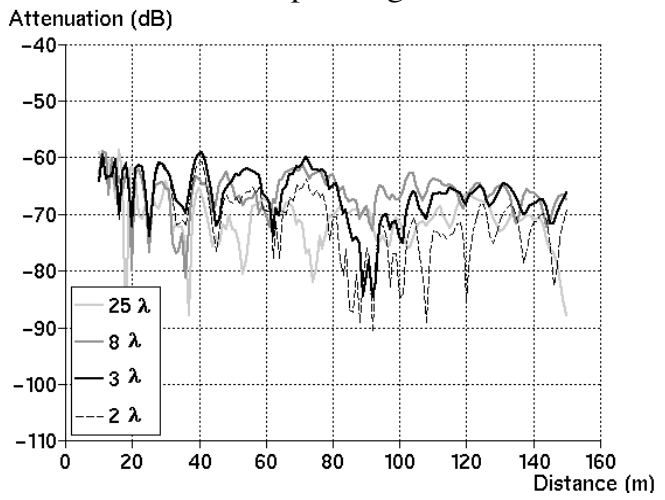

Figure 4.1: Results for Tunnel C vs. facets size $2.4 \mathrm{GHz}$

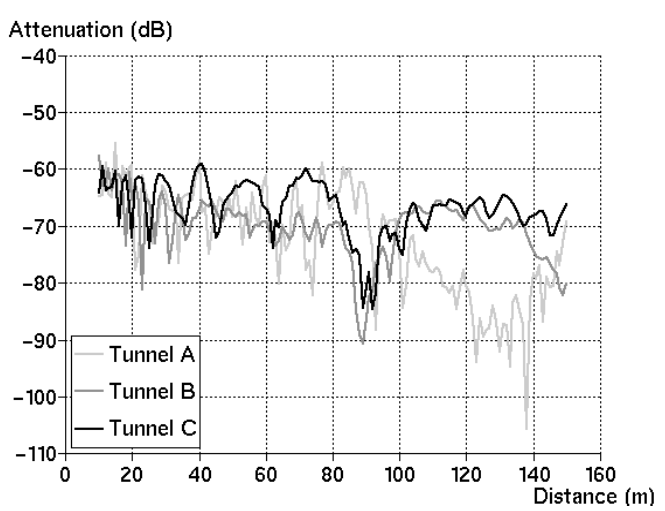

Figure 4.2: Results for Tunnels A, B and C $($ facets size $=3 \lambda)-2.4 \mathrm{GHz}$ 


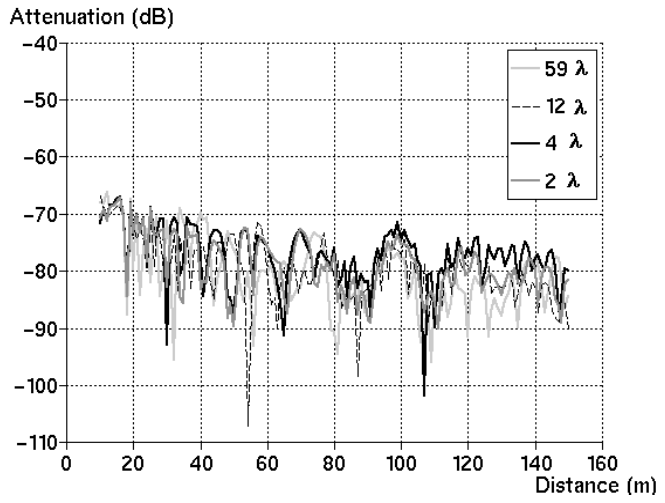

Figure 4.3: Results for Tunnel C vs. facets size $5.8 \mathrm{GHz}$

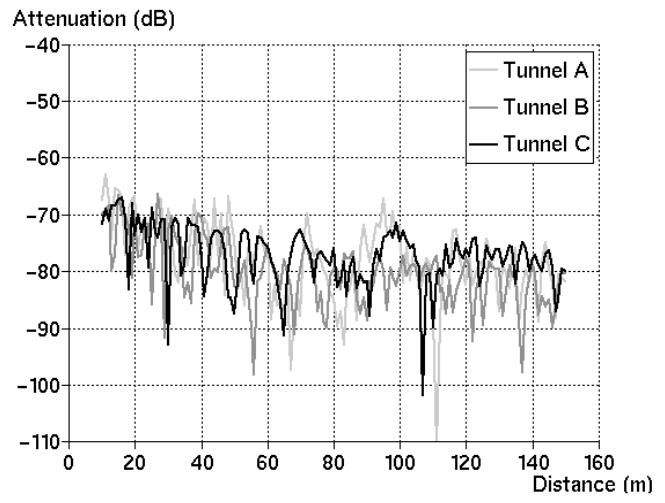

Figure 4.4: Results for Tunnels A, B and C (facets size: $4 \lambda$ ) $-5.8 \mathrm{GHz}$

\section{B. Influence of Tunnel dimensions}

Tunnels with small cross section, such as mass transit tunnels, are considered in this part. Tunnel A represents a square cross section tunnel with a size of $4.5 \mathrm{~m}$, tunnel $\mathrm{B}$ is an arched cross section tunnel modeled by 3 facets, and tunnel $\mathrm{C}$ is an arched cross section tunnel modeled by $n$ facets.

Simulations are performed at $1 \mathrm{GHz}, 2.4 \mathrm{GHz}$ and $5.8 \mathrm{GHz}$. The transmitting and receiving antennas are dipoles vertically polarized and placed respectively in $(2.25,0,3.5) \mathrm{m}$ and $(1, y, 1.5) \mathrm{m}, y$ varying from $10 \mathrm{~m}$ to $150 \mathrm{~m}$ with a step of $1 \mathrm{~m}$. High frequency conditions give the following constraints on the number of facets: at $1 \mathrm{GHz}$ :

$$
4 \leq n \leq 11
$$

at $2.4 \mathrm{GHz}$ :

$$
4 \leq n \leq 28
$$

at $5.8 \mathrm{GHz}$ :

$$
4 \leq n \leq 68
$$

Figures 4.5, 4.7 and 4.9 illustrate results obtained for tunnel $\mathrm{C}$ at the 3 frequencies depending on the facets size. Figures 4.6, 4.8 and 4.10 show the results for tunnels A, $\mathrm{B}$ and $\mathrm{C}$ (considering a facets size providing the higher signal level) to illustrate the effect of section geometry.

Similar conclusions to the previous ones can be made in the case of small tunnels. An important variation is observed on the signal level for different facets sizes. A «focusing » effect for the arched section is also highlighted compared to the rectangular one.

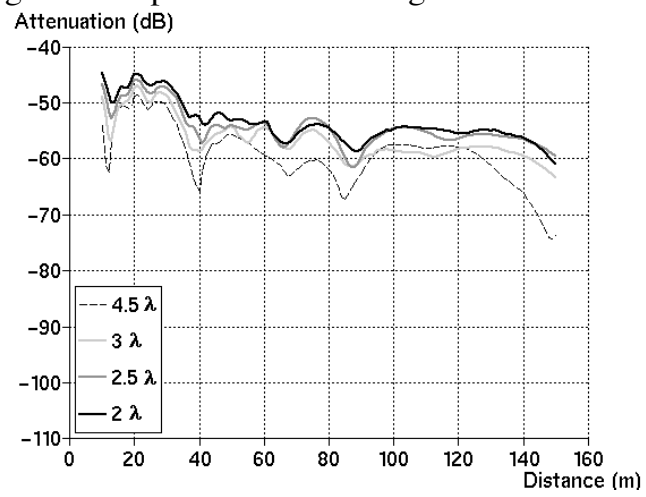

Figure 4.5: Results for Tunnel C vs. facets size $1 \mathrm{GHz}$

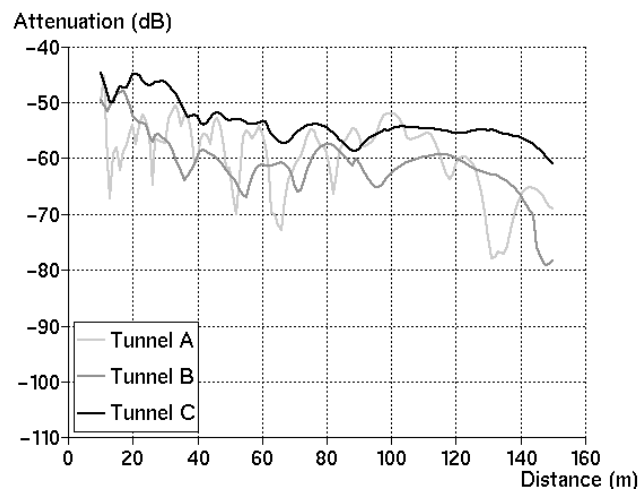

Figure 4.6: Results for Tunnels A, B and C $($ facets size $=2 \lambda)-1 \mathrm{GHz}$

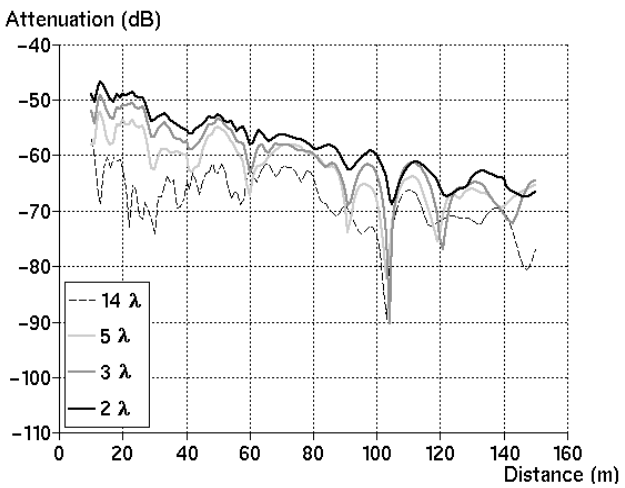

Figure 4.7: Results for Tunnel C vs. facets size $2.4 \mathrm{GHz}$

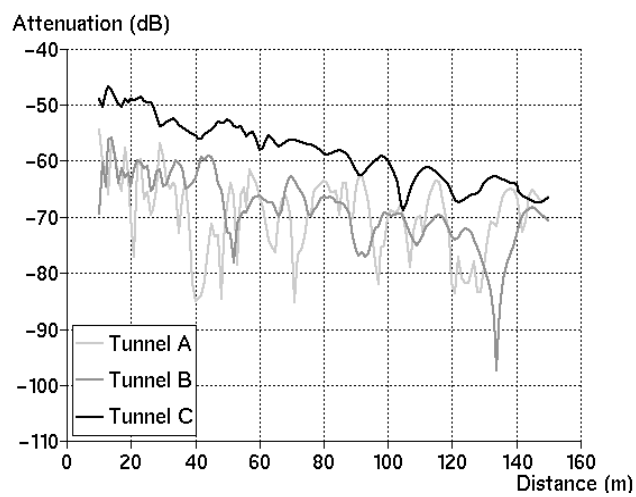

Figure 4.8: Results for Tunnels A, B and C $($ facets size $=2 \lambda)-2.4 \mathrm{GHz}$ 

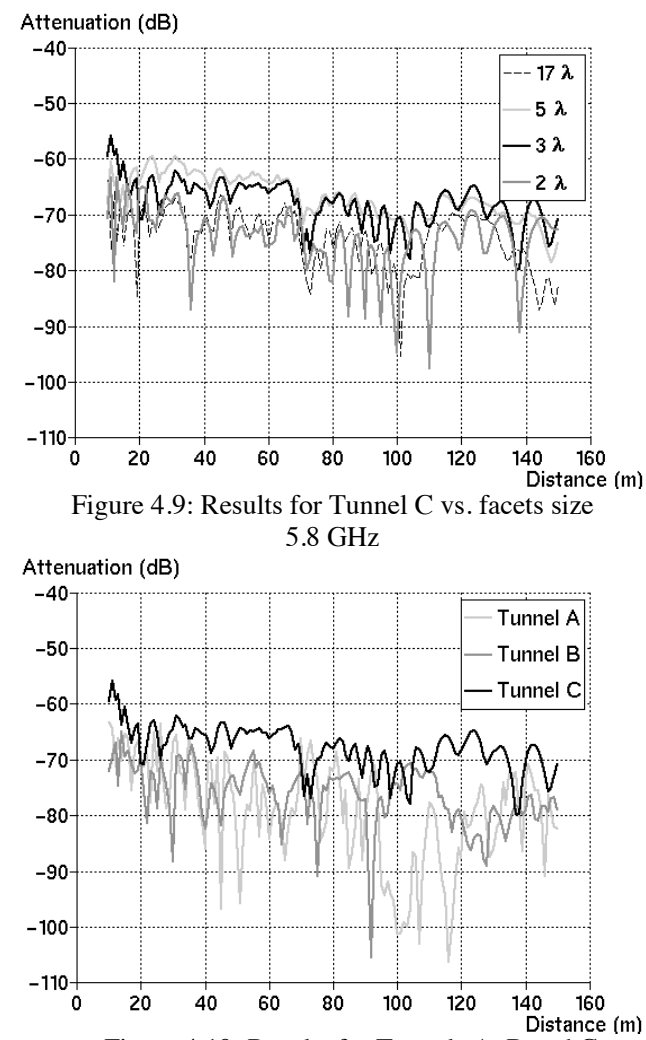

Figure 4.10: Results for Tunnels A, B and C

$($ facets size $=3 \lambda)-5.8 \mathrm{GHz}$

\section{MEASUREMENT RESULTS}

\section{A. Trial conditions}

Measurements were conducted in the Tunnel of Roux, which is a two ways arched cross section straight road tunnel located in Ardèche region in France. This tunnel is perfectly straight and has a length of $3,336 \mathrm{~m}$ (Figure 5.1). The transverse section of the tunnel is semicircular and has a diameter of $8.3 \mathrm{~m}$. The maximum height is $5.8 \mathrm{~m}$ at the centre of the tunnel. The transmitting part is static. It is composed of a large bandwidth horn antenna $(9.2 \mathrm{dBi}$ gain at $2.4 \mathrm{GHz}$, $10.1 \mathrm{dBi}$ gain at $5.8 \mathrm{GHz}$ ), vertically polarized, and connected by a low loss cable $(63 \mathrm{~dB} / 100 \mathrm{~m}$ at $2.4 \mathrm{GHz}$, $100 \mathrm{~dB} / 100 \mathrm{~m}$ at $5.8 \mathrm{GHz}$ ) to a transmitter delivering a sinusoidal signal at the required frequency. The mobile reception system is composed of the same horn antenna, also vertically polarized, and connected by a low loss cable to a THALES VUH-TRC8025 receiver used in an analyzer mode and allowing an acquisition rate of 6 points/sec, which corresponds to one measurement every $\lambda / 2$ at $2.4 \mathrm{GHz}$ with a speed of $1.4 \mathrm{~km} / \mathrm{h}$. The system is installed on a go-kart allowing a very small and regular velocity.

Two different configurations of transmitter-receiver locations have been studied, as is shown in Figure 5.2. The EP1-RP1 configuration corresponds to a transmitter located in the center of the cross section, at $(3.2,0,4.8) \mathrm{m}$ and a receiver in the middle of one of the two ways, at $(2.4, y, 4.1) \mathrm{m}$, where $y$ represents the longitudinal direction of the tunnel and varies from $1 \mathrm{~m}$ to $500 \mathrm{~m}$ with a step of $0.0125 \mathrm{~m}$. For the EP2-RP1 configuration the transmitter is moved near the tunnel wall at $(1.9,0,4.8) \mathrm{m}$.

The measurements were conducted at $2.4 \mathrm{GHz}$ and $5.8 \mathrm{GHz}$.

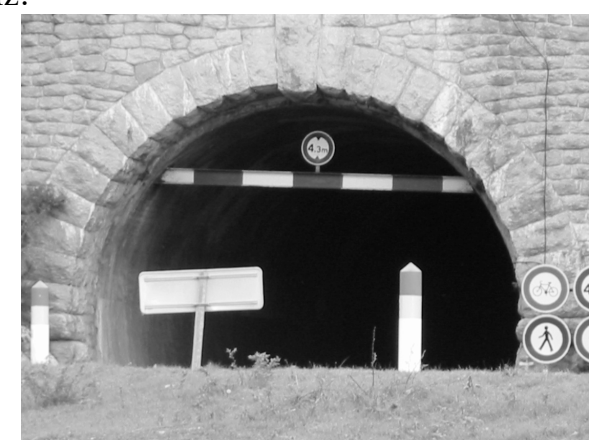

Figure 5.1: Tunnel of Roux

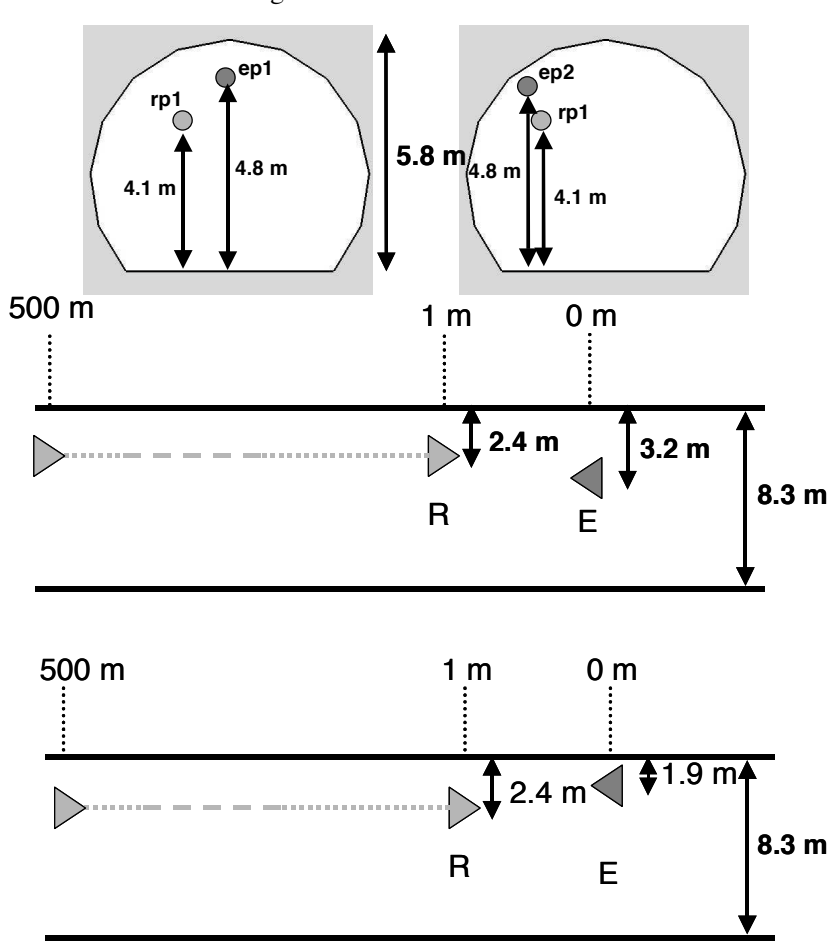

Figure 5.2: Measurement configurations

\section{B. Measurement results}

All the results presented are normalized by the maximum of the received power along the tunnel in order to eliminate the effects of antenna gain and cable loss. Figures 5.3 and 5.4 illustrate measurement results at $2.4 \mathrm{GHz}$ and $5.8 \mathrm{GHz}$ for the EP1-RP1 and EP2-RP1 configurations respectively. For the first configuration (cf. figure 5.3), we can observe a very weak influence of the frequency on the received power. In the second configuration, the attenuation is lower at $5.8 \mathrm{GHz}$ compared to $2.4 \mathrm{GHz}$. These results are similar to the results obtained by modal theory for the case of rectangular tunnel [12]. These two configurations have been tested to evaluate the influence of transmitter location in the cross section. In our case, no major difference is observed from one location to another. 


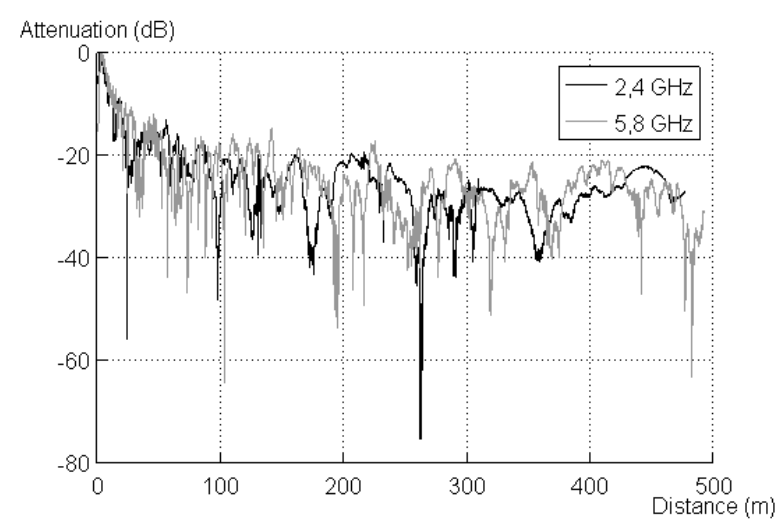

Figure 5.3: Measurement results EP1-RP1 configuration

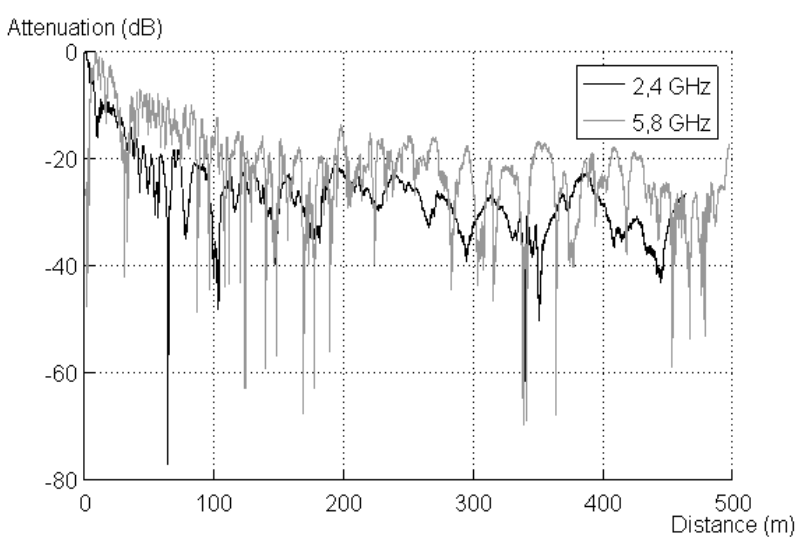

Figure 5.4: Measurement results EP2-RP1 configuration

\section{Comparison of simulation and measurement results}

The configurations of measurements were reproduced in simulations using our tessellation approach of the cross section.

Once again, to guarantee the validity of the high frequency hypothesis, some conditions on the number of facets $n$ have to be satisfied according to the given tunnel: at $2.4 \mathrm{GHz}$ :

$$
4 \leq n \leq 66
$$

at $5.8 \mathrm{GHz}$ :

$$
4 \leq n \leq 160
$$

Figures 5.5 and 5.6 illustrate the simulated received power for different facets sizes compared to the measured power, for the EP1-RP1 configuration at $2.4 \mathrm{GHz}$. Globally, we can note a good concordance between measurements and simulations, whatever the facets size. To determine the best facets size, we proposed the following method.

To be free of fast fading variations, we smooth the received signal by using a running mean. The window's length is $40 \lambda$, on the first 50 meters, and $100 \lambda$ for the rest [13]. Then for each simulation, i.e. for each tessellation, the standard deviation is calculated between the measured and simulated mean powers. Different zones were considered to evaluate the behavior of configurations in relation to the transmitter-receiver distance. Table I presents the results obtained for the EP1-RP1 configuration at $2.4 \mathrm{GHz}$. The bold values present the lowest standard deviations which potentially correspond to the best tessellation. A similar study was conducted at $5.8 \mathrm{GHz}$. The simulation results are illustrated in Figures 5.7 and 5.8. Table II presents the quantitative analysis. The results led to different conclusions. The two tables, Tables I and II, show that, despite a good matching between simulations and experimentations, we cannot conclude on one preferable size of facets or another. In the following paragraph, we present a statistical analysis of the fast fadings on the measured and simulated data.

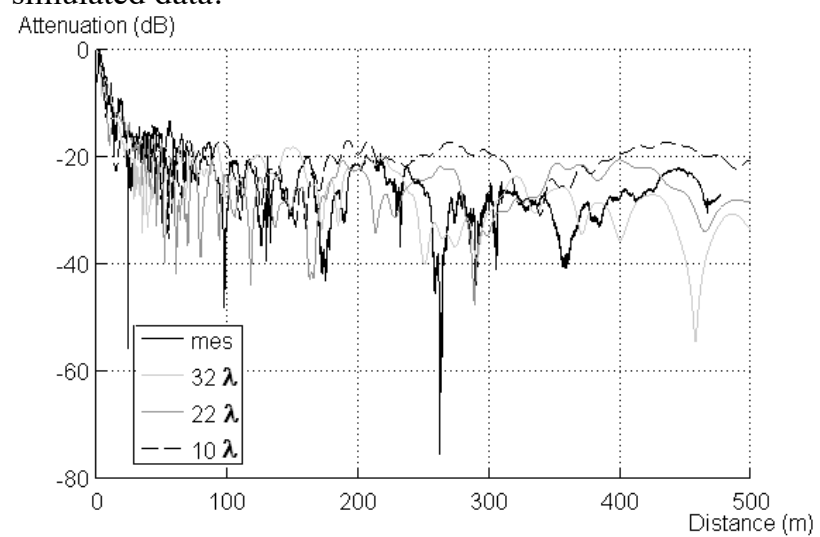

Figure 5.5: Simulation results vs. facets size EP1-RP1 configuration - $2.4 \mathrm{GHz}$ (1)

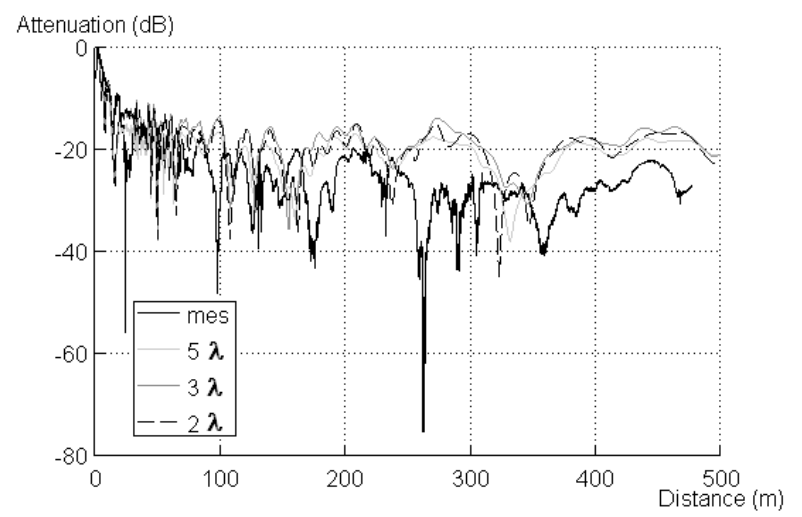

Figure 5.6: Simulation results vs. facets size EP1-RP1 configuration $-2.4 \mathrm{GHz}(2)$

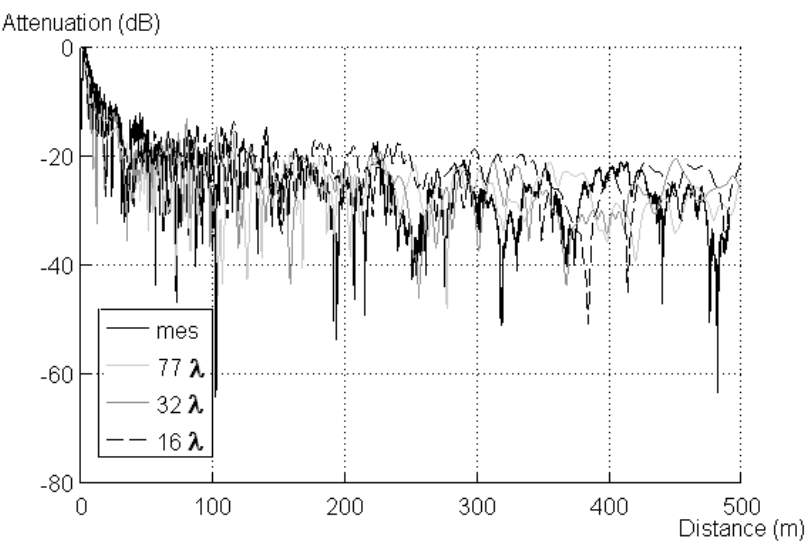

Figure 5.7: Simulation results vs. facets size EP1-RP1 configuration $-5.8 \mathrm{GHz}(1)$ 


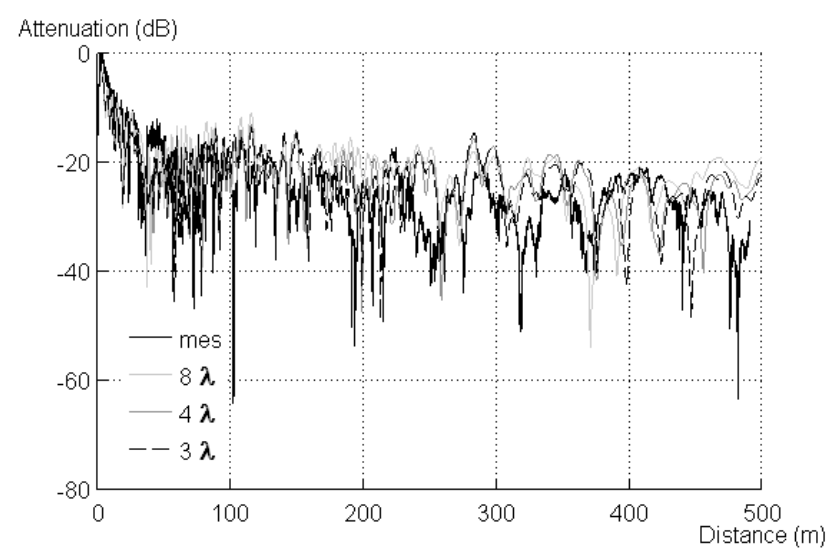

Figure 5.8: Simulation results vs. facets size EP1-RP1 configuration $-5.8 \mathrm{GHz}(2)$

TABLE I.

STANDARD DEVIATION (IN DB) OF SIMULATIONS COMPARED TO MEASUREMENTS (EP1-RP1 2.4 GHZ)

\begin{tabular}{|c|c|c|c|c|c|}
\hline $\begin{array}{c}\text { Facet Zone } \\
\text { size }\end{array}$ & $\begin{array}{c}\mathbf{0 m -} \\
\mathbf{5 0 0 m}\end{array}$ & $\begin{array}{c}\mathbf{0 m -} \\
\mathbf{5 0 m}\end{array}$ & $\begin{array}{c}\mathbf{5 0 m -} \\
\mathbf{1 5 0 m}\end{array}$ & $\begin{array}{c}\mathbf{1 5 0 m}-\mathbf{3 5 0 m} \\
\mathbf{3 5 0 m}\end{array}$ & $\begin{array}{c}\mathbf{3 5 0 0 m} \\
\mathbf{5 0 0 m}\end{array}$ \\
\hline $\mathbf{3 2} \boldsymbol{\lambda}$ & 5.24 & 5.48 & 3.59 & 5.76 & 11.33 \\
\hline $\mathbf{2 2} \boldsymbol{\lambda}$ & 5.48 & 3.64 & 4.85 & 6.23 & 10.92 \\
\hline $\mathbf{1 0} \boldsymbol{\lambda}$ & 6.50 & 3.70 & 3.57 & 8.97 & 11.07 \\
\hline $\mathbf{5} \boldsymbol{\lambda}$ & 6.43 & 3.73 & 4.31 & 8.81 & 11.19 \\
\hline $\mathbf{3} \boldsymbol{\lambda}$ & 7.90 & 3.94 & 5.83 & 10.31 & 12.49 \\
\hline $\mathbf{2} \boldsymbol{\lambda}$ & 7.08 & 3.97 & 5.17 & 9.29 & 12.10 \\
\hline
\end{tabular}

TABLE II.

STANDARD DEVIATION (IN DB) OF SIMULATIONS COMPARED TO MEASUREMENTS (EP1-RP1 5.8 GHz)

\begin{tabular}{|c|c|c|c|c|c|}
\hline $\begin{array}{c}\text { Facet } \\
\text { size }\end{array}$ & $\begin{array}{c}\mathbf{0 m -} \\
\mathbf{5 0 0 m}\end{array}$ & $\begin{array}{c}\mathbf{0 m -} \\
\mathbf{5 0 m}\end{array}$ & $\begin{array}{c}\mathbf{5 0 m -} \\
\mathbf{1 5 0 m}\end{array}$ & $\begin{array}{c}\mathbf{1 5 0 m -} \\
\mathbf{3 5 0 m}\end{array}$ & $\begin{array}{c}\mathbf{3 5 0 m -} \\
\mathbf{5 0 0 m}\end{array}$ \\
\hline $\mathbf{7 7} \boldsymbol{\lambda}$ & 5.33 & 5.15 & 6.09 & 3.89 & 6.46 \\
\hline $\mathbf{3 2} \boldsymbol{\lambda}$ & 5.07 & 5.52 & 3.50 & 4.84 & 5.70 \\
\hline $\mathbf{1 6} \boldsymbol{\lambda}$ & 6.06 & 4.42 & 3.36 & 7.19 & 6.10 \\
\hline $\mathbf{8} \boldsymbol{\lambda}$ & 6.60 & 4.87 & 4.25 & 7.98 & 6.13 \\
\hline $\mathbf{4} \boldsymbol{\lambda}$ & 5.81 & 6.01 & 3.13 & 6.54 & 5.93 \\
\hline $\mathbf{3} \boldsymbol{\lambda}$ & 5.57 & 6.42 & 3.06 & 6.12 & 5.88 \\
\hline
\end{tabular}

D. Statistical analysis of fast fading

The two previous windows are considered to perform a running mean that is then subtracted from the signal in order to extract its fast variations. A comparison between measured and simulated data is realized. For the simulations, we consider the configuration that gives the nearest results compared to experimentations. For the EP1-RP1 configuration at $2.4 \mathrm{GHz}$, this corresponds to a tessellation size of $32 \lambda$.

The Cumulative Density Functions of the measured and simulated data are calculated. They are both compared to the Rayleigh, Weibull and Nakagami distributions. We used the Kolmogorov-Smirnov test in order to decide which distribution best fits the results. Figures 5.9 and 5.10 show the Cumulative Density Functions of the measured and simulated data respectively compared to the fitted models for the EP1-RP1 configuration at $2.4 \mathrm{GHz}$. The parameters of the theoretical distributions are determined by Maximum Likelihood estimators. The same analysis was also realized for the other configurations and frequencies, and similar results were obtained. The analysis shows a similar behavior for both measured and simulated data. The curves show that the Weibull distribution fits both the measurement and the simulation statistics quite well [14], [15].

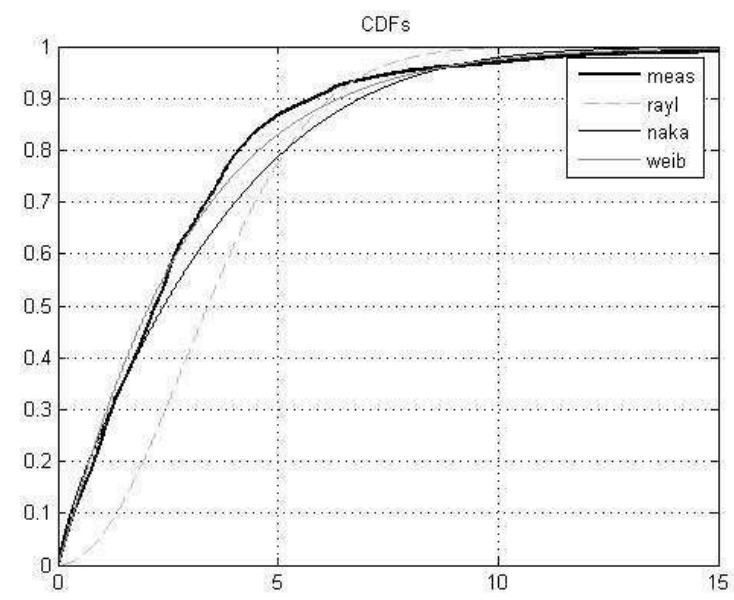

Figure 5.9: Measured data and fitted distributions

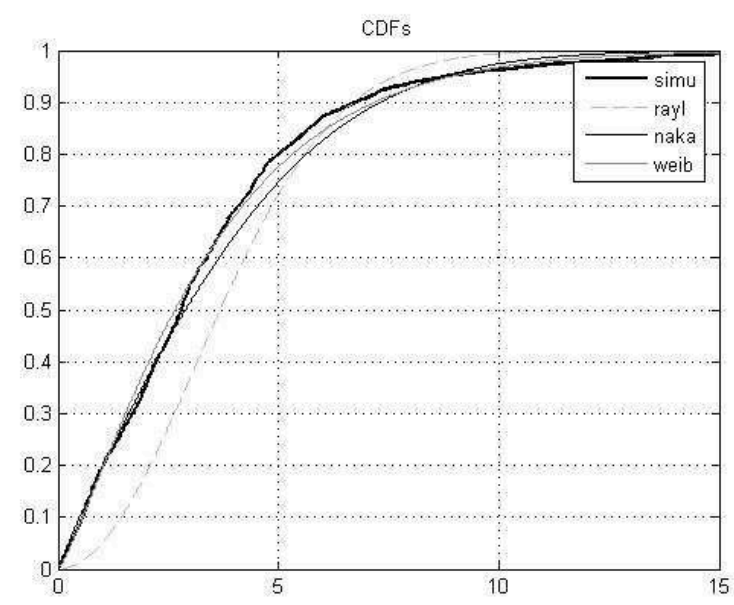

Figure 5.10: Simulated data and fitted distributions

\section{CONCLUSIONS}

This paper illustrates a method to model the radio wave propagation in tunnels. After the presentation of several possible techniques found in the literature, we detailed the results obtained using a Ray-Tracing process combined with a tessellation of an arched cross section straight tunnel. The influences of signal frequency and tunnel dimensions were analyzed. Finally, some measurements were performed in real conditions in a road tunnel.

We realized the study on three configurations of straight tunnels. It allows us to observe a «focusing » effect on the received signal for the arched section compared to the rectangular section, even if this phenomenon is less marked at higher frequencies. The 
study was conducted at $1 \mathrm{GHz}, 2.4 \mathrm{GHz}$ and $5.8 \mathrm{GHz}$. Two dimensions of tunnels were considered: a large tunnel (TGV type) and a small tunnel (mass transit type). An important variation in signal level can be observed for different facets length. A compromise has to be found on the number of facets. It has to be sufficient to represent the geometry of the arched section but not too large to respect the limits of the physical model based on a high frequency approach.

The simulations with the tessellation approach were then compared to measurements performed in an arched cross section straight road tunnel. An analysis on slow fadings and fast fadings is made on the results. The comparisons in terms of slow fading were realized by the calculation of standard deviations. Cumulative Distribution functions were computed on the fast fadings and fitted with classical statistical distributions.

We observed that the results obtained with the tessellation approach depend on the facets size. An optimal facets length cannot be defined. However, a good concordance with measurement results is observed in terms of average signal level and fast fading statistics.

The tessellation of the cross section into multiple planar facets was a first approach to model the wave propagation in non-rectangular tunnels. The results presented for different configurations and different frequencies do not allow us to set up any conclusion in terms of optimal number of facets and optimal length. Consequently, we envisaged as the continuation of this work, to consider another solution, based on ray launching techniques associated to real curved surfaces. At the same time, we envisage to compare the presented simulation results with those obtained with exact methods, such as FDTD on small sections, for computation time reasons.

\section{ACKNOWLEDGMENT}

The authors would like to thank the ALSTOM-TIS (Transport Information Solution) who supported this work.

\section{REFERENCES}

[1] S.-H. Cheng and S.-K. Jeng. SBR image approach for radio wave propagation in tunnels with and without traffic. IEEE Transactions on Antennas and Propagation, 45(3):570-578, 1996.

[2] Y.P. Zhang, Y. Hwang, and R.G. Kouyoumjian. Rayoptical prediction of radio-wave propagation characteristics in tunnel environments part 1: Theory, IEEE Transactions on Antennas and Propagation, vol. 46, no. 9, pp. 1328-1336, 1998

[3] J.M. Molina-Garcia-Pardo, M. Lienard, A. Nasr and P. Degauque. Wideband Analysis of Large Scale and Small Scale Fading in Tunnels, ITST08, Phuket, Oct. 2008.

[4] Document Cost231 TD 031 - Thomas Klemenschits, Ernts Bonek - « Radio Coverage of Tunnels by Discrete Antennas: Measurement and prediction », 1995.

[5] C. A. Balanis. Advanced Engineering Electromagnetics. John Wiley \& Sons, 1989.

[6] T.-S. Wang and C.-F. Yang. Simulations and measurements of wave propagations in curved road tunnels for signals from GSM base stations. IEEE Transactions on Antennas and Propagation, 54(9):2577-2584, 2006.

[7] R. P. Torres, L. Valle, M. Domingo, S. Loredo, and M. C. Diez. CINDOOR: An engineering tool for planning and design of wireless systems in enclosed spaces. IEEE Antennas and Propagation Magazine, 41(4), 1999.

[8] D. Didascalou. Ray-optical Wave Propagation Modelling in Arbitrarily Shaped Tunnels. Ph.D. dissertation, University of Karlsruhe, Germany, feb. 2000.

[9] S. Baranowski, G. Bourdier, and P. Degauque. Optimisation des règles d'ingénierie radio-modélisation de la propagation d'ondes radioélectriques en tunnels courbes. Convention d'études INRETS/USTL 1997/L1, Laboratoire de Radio propagation et Electronique, Villeneuve d'Ascq, avril 1998.

[10] D. Didascalou, J. Maurer, and W. Wiesbeck. Subway tunnel guided electromagnetic wave propagation at mobile communications frequencies. IEEE Trans. Antennas Propag., vol. 49, pp. 1590-1596, Nov. 2001.

[11] L. Aveneau, P. Combeau, R. Vauzelle and M. Mériaux. Efficient computation of radio coverage zone using a spatial partionment approach. IEEE VTC03, Orlando, USA, Oct. 2003.

[12] Collin R.E. Field Theory of Guided Waves, IEEE Press, Piscataway, 2nd edition, 1991.

[13] M. Lienard, P. Degauque. Propagation in Wide Tunnels at $2 \mathrm{GHz}$ : A statistical analysis. IEEE Transactions on Vehicular Technology, vol. 47, n4, nov 1998.

[14] M. D. Yacoub, "The alpha-mu General Fading Distribution", Proc. Of IEEE International Symposium on Personal, Indoor, Mobile Radio Communications, Lisbon (Portugal), Sept. 2002.

[15] N. C. Sagias and G. K. Karagiannidis, "Gaussian class multivariate Weibull distributions: Theory and applications in fading channels", IEEE Transactions on Information Theory, 51 (10), 3608-3619, 2005.

Emilie Masson was born in Armentières, France, on October 21, 1982. She received the Engineer degree from the Institut Supérieur de l'Electronique et du Numérique, Lille, in 2005.

Currently, she works as a PhD student in ALSTOMTransport (Saint-Ouen) and she is tutored by the LEOST (Transport Electronics and Signal Processing laboratory) of INRETS (French National Institute for research on Transport and Safety) and the Xlim UMR CNRS 6172 SIC Laboratory of the University of Poitiers. She is working in the field of electromagnetic wave propagation in non-rectangular and curved tunnels for railway and mass transit applications.

Pierre Combeau was born in Angoulême, France, on June 12, 1978. He received the M.S. degree in mobile radiocommunication and image processing and the Ph.D. degree in signal processing and telecommunications from the University of Poitiers, respectively in 2001 and 2004.

Since 2005, he is professor assistant at the University of Poitiers in the department SIC (Signal Image 
Communications) of the Xlim Laboratory. His fields of expertise include the study of the electromagnetic waves propagation for the SISO and MIMO wireless communication systems.

Marion Berbineau was born in Toulouse, France, on September 18, 1962. She received the Engineer degree in electronics, automatic and metrology from Polytech'Lille (France) and the $\mathrm{PhD}$ in electronics from the University of Lille respectively in 1986 and 1989.
She joined INRETS as a full time researcher in telecommunications in 1989. She is currently Research Director and Director of the LEOST laboratory.

Dr Berbineau field of expertise are EM propagation, channel characterization and modeling for transport environments, signal processing for wireless communication systems, MIMO systems. She is involved in several national and European projects. She is author and co-author of several publications and patents. Dr Berbineau is an IEEE member, affiliated to the VTS society. 